\title{
Authoritative classroom climate and its relations to bullying victimization and bystander behaviors
}

Robert Thornberg, Linda Wänström and Tomas J ungert

The self-archived postprint version of this journal article is available at Linköping University Institutional Repository (DiVA):

http:/ / urn.kb.se/ resolve?urn=urn:nbn:se:liu:diva- 153512

N.B.: When citing this work, cite the original publication.

Thornberg, R., Wänström, L., J ungert, T., (2018), Authoritative classroom climate and its relations to bullying victimization and bystander behaviors, School Psychology International, 39(6), 663-680.

https:// doi.org/ 10.1177/ 0143034318809762

Original publication available at:

https:/ / doi.org/ 10.1177/ 0143034318809762

Copyright: SAGE Publications (UK and US)

http:// www.uk.sagepub.com/home.nav 
Authoritative Classroom Climate and Its Relations to Bullying Victimization and Bystander

$$
\begin{aligned}
& \text { Behaviors } \\
& \text { Robert Thornberg }^{\text {a }} \\
& \text { Linda Wänström }^{\text {b }} \\
& \text { Tomas Jungert }^{c}
\end{aligned}
$$

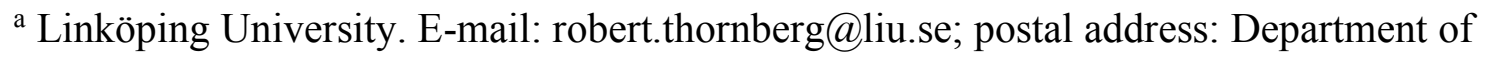
Behavioral Sciences and Learning, Linköping University, SE-58183 Linköping, SWEDEN

b Linköping University. E-mail: linda.wanstrom@liu.se; postal address: IDA, Linköping University, SE-58183 Linköping, SWEDEN

${ }^{c}$ Lund University. E-mail: tomas.jungert@lu.se; postal address: Department of Psychology, Lund University, SE-22100 Lund, SWEDEN

Corresponding author: Robert Thornberg, $\mathrm{PhD}$, Professor

\section{Acknowledgement}

This research was supported by a grant awarded to Robert Thornberg from The Swedish Research Council [grant number D0775301].

\section{Compliance with ethical standards}

Conflict of interest: The authors declare that they have no conflicts of interest. 


\begin{abstract}
Authoritative school climates have been associated with less school bullying and other antisocial behaviors. However, studies focusing on the classroom level, as well as on bystander behaviors, are lacking. The aim of the current study was to examine whether authoritative classroom climates were associated with bullying victimization and various bystander behaviors (reinforcer, outsider, and defender behaviors) in school bullying. We included gender as a covariate at the individual and classroom levels. Participants were 1540 fifth-grade students (824 girls) from 104 classrooms in Sweden who filled out a questionnaire. The findings revealed that girls and students in classes with greater authoritative classroom climates were more inclined to defend. Boys reinforced more as did students in classes with more boys and more authoritative classroom climates. Boys showed more outsider behaviors as did students in classes with less authoritative classroom climates. Students in classrooms with less authoritative climates were victimized to a higher degree. Thus, the current findings suggest that a warm, caring, supportive, controlled, demanding, and cohesive classroom climate should be considered a vital protective factor against bullying victimization and negative bystander responses, and a facilitator of defending and supporting victims.
\end{abstract}


Authoritative Classroom Climate and Its Relations to Bullying Victimization and Bystander Behaviors

Bullying, usually defined as repeated aggression toward someone in a less powerful situation (Olweus, 2010), is a worldwide problem in schools (Chester et al., 2015). Being bullied in school is associated with a greater risk of mental health problems such as depression, anxiety, suicidal ideation and behavior, and psychosomatic symptoms and problems in childhood and adolescence (Gini \& Pozzoli, 2013; Holt et al., 2015; Silberg, Copeland, Linker, Moore, Roberson-Nay, \& York, 2016). Victims of school bullying are also at greater risk of suffering from mental and physical health problems in adulthood (Copeland, Wolke, Angold, \& Costello, 2013; Copeland, Wolke, Lereya, Shanahan, Worthman, \& Costello, 2014; Evans-Lacko et al., 2017; Meltzer, Vostanis, Ford, Bebbington, \& Dennis, 2011; Silberg et al., 2016).

Further, in most bullying episodes, peers are present as bystanders (Atlas \& Pepler, 1998; Hawkins, Pepler, \& Craig, 2001). The participant role model (Salmivalli, 1999) states that peers can take different social roles in bullying situations as a result of the interplay between group processes, the expectations of others, and individual behavioral dispositions. In addition to the bully role and the victim role, there are four possible bystander roles. Assistants are individuals who join in and help the ringleader bullies. Reinforcers are individuals who support and thus signal their approval of the bullying by laughing or cheering. Outsiders are individuals who remain passive and try to stay away. Defenders are individuals who help and support the victim, and who therefore may display disapproval of the bullying or toward the bully depending on whether their intervention is more direct (e.g., telling the bully to stop bullying) or indirect (e.g., comforting the victim). In the current study, we were interested in bystander behaviors in addition to bullying victimization because large- 
scale studies have demonstrated that the more classmates reinforce bullying and fail to defend the victims, the more likely it is that bullying will continue (Kärnä, Voeten, Poskiparta, \& Salmivalli, 2010; Nocentini, Menesini, \& Salmivalli, 2013; Salmivalli, Voeten, \& Poskiparta, 2011).

In order to develop strategies to prevent bullying, school psychologists need to understand its link to school contextual factors. Further, understanding how such factors are related to various bystander behaviors in bullying is crucial as well in bullying prevention as we need to increase defender behaviors and decrease reinforcer behaviors among students in order to decrease bullying victimization. According to the social-ecological framework (Espelage \& Swearer, 2011; Hong \& Espelage, 2012), victimization and bystander responses in school bullying are ecological phenomena in which contextual variables such as school climate and classroom climate play important roles.

\section{School and Classroom Climate}

Although there is a lack of consensus about how to define and measure school climate (Wang \& Degol, 2016), Bradshaw, Waasdorp, Debnam, and Johnson (2014) define it as "the shared beliefs, values, and attitudes that shape interactions between students, teachers, and administrators and set the parameters of acceptable behaviors and norms for the schools" (p. 594). As a construct, school climate often includes the quality of teacher-student and studentstudent relationships, orders/rules/discipline, school safety, and school connectedness/belongingness aggregated at the school level (Bear, Gaskins, Blank, \& Chen, 2011; Zullig, Koopman, Patton, \& Ubbes, 2010). Whereas the social-ecological framework emphasizes that individual behaviors are shaped by the school environment, such as the school climate, the risk and resilience perspective focuses on risk and protective factors within the school environment, and how the quality of school climate may increase or decrease a student's probabilities of positive and negative outcomes (Wang \& Degol, 2016). 
A positive school climate can be considered as a protective factor because it has been associated with less aggression and fewer behavioral problems (for a review, see Thapa, Cohen, Guffey, \& Higgins-D’Alessandro, 2013), including bullying perpetration and victimization (Fink, Patalay, Sharpe, \& Wolpert, 2018; Konishi, Miyazaki, Hymel, \& Waterhouse, 2017; La Salle, George, McCoach, Polk, \& Evanovich, 2018; Modin, Låftman, \& Östberg, 2017; White, La Salle, Jeffrey, \& Meyers, 2014).

Classroom climate in turn can be defined as "the sum of all the group processes that take place during teacher-student and student-student interactions" (Zedan, 2010, p. 76), and includes interpersonal relationships and level of teacher control. Whereas the school climate is the overall climate of the school (school level), the classroom climate is a part of the school climate that varies across classrooms (classroom level). Although it has been found to be associated with academic achievement (for a systematic review, see Hattie, 2009), the question of whether classroom climate may be linked to bullying victimization and bystander behavior in bullying is still overlooked in the research literature, with a few exceptions. One previous study found that a poor class climate, in terms of student-student relationships at the classroom level, was associated with greater victimization (Stefanek et al., 2011). Findings from a more recent study suggest that peer victimization is less likely to occur in classrooms characterized by positive, warm, fair, and supportive relationships among students and between teachers and students (Thornberg, Wänström, \& Pozzoli, 2017). A multilevel study conducted by Thornberg, Wänström, Hong, and Espelage (2017), found that positive, warm, and supportive student-student relationship patterns at the classroom level were associated with more frequent defender behaviors.

In the current study, we focus on the classroom climate for three reasons. First, there are significant between-classroom variations in victimization and bystander behaviors in school bullying (Atria, Strohmeier, \& Spiel, 2007; Coelho \& Sousa, 2018; Salmivalli, Voeten, \& 
Poskiparta, 2011; Stefanek, Strohmeier, van de Schoot, \& Spiel, 2011). Second, in Sweden (the focus of the current study) as well as in other countries, elementary school students usually remain in a single school class with the same classmates for the full school day and for more than one year. Third, fewer studies have examined classroom climate as compared to school climate in relation to bullying prevalence. Ramelow, Currie, and Felder-Puig (2015) argue that school climate is a multi-dimensional and complex phenomenon, and its measurement should therefore be grounded in theory. We would like to add that this argument is also valid in the case of studying classroom climate, and we have therefore adopted the authoritative school climate model.

Authoritative school climate and classroom climate. With reference to Baumrind's (1967, 1971, 1989) classic work on authoritative parenting and its positive outcomes (for a comprehensive review, see Larzelere, Morris, \& Harrist, 2013), researchers have proposed the authoritative school climate (Gregory \& Cornell, 2009; Gregory, Cornell, Fan, Sheras, Shih, \& Huang, 2010; Konold \& Cornell, 2015) as a theoretical framework for conceptualizing a positive school climate. This model highlights two dimensions of school climate: support (responsiveness) and structure (demandingness). Support refers to the degree to which students feel supported and respected by their teachers, including experiences of warmth, care, and open communication. Structure refers to strict but fair enforcement of school rules and high academic expectations and demandingness. An authoritative school climate thus refers to a school climate with high levels of both support and structure. A growing body of research has shown that an authoritative school climate is linked to lower levels of bullying and victimization (Cornell \& Huang, 2016; Cornell, Shekla, \& Konold, 2015; Gerlinger \& Wo, 2014; Gregory et al., 2010).

In the current study, we have developed and conceptualized the authoritative classroom climate as a classroom interaction and relationship pattern characterized by high levels of 
teacher support, warmth and responsiveness, high levels of teacher structure and demandingness, and high levels of student support, warmth and responsiveness. Whereas Thornberg et al. (2017) examined the supportiveness, warmth, or responsiveness of both teachers and classmates, we have also included teacher structure/demandingness. This is the first study, as far as we know, to investigate whether an authoritative classroom climate is related to bullying victimization and defender, outsider, and reinforcer behaviors in school bullying.

\section{Gender Differences in Bullying}

Findings on gender differences in victimization are mixed (Hong \& Espelage, 2012). In their meta-analysis, Cook, Williams, Guerra, Kim, and Sadek (2010) found that gender had a weak but significant effect as a predictor of bullying perpetration meaning that boys tended to engage more in bullying than girls (also see Álvarez-García, García, \& Núñez, 2015), although gender failed to significantly predict bullying victimization. In regard to bystander behavior, studies have shown that boys are more engaged in reinforcer behaviors than girls, whereas girls are more engaged in defender behaviors than boys (Coelho \& Sousa, 2018; Espelage, Green, \& Polanin, 2012; Gini, Pozzoli, \& Bussey, 2015; Pöyhönen, Juvonen, \& Salmivalli, 2012; Thornberg \& Jungert, 2013). Because boys are more inclined than girls to engage in bullying perpetration, it seems plausible to expect a higher frequency of victimization in classrooms with more boys (cf., Coelho \& Sousa, 2018). On the other hand, findings in the literature are inconsistent. In some studies, bullying was found to be more frequent in classrooms with a higher proportions of boys, whereas others did not find any classroom-level effect of the gender distribution on peer victimization (for a review, see Saarento, Garandeau, \& Salmivalli, 2015).

\section{The Current Study}


The aim of the current study was to examine whether authoritative classroom climates are associated with bullying victimization and various bystander behaviors (reinforcer, outsider, and defender behaviors) in school bullying. Considering the protective characteristics of authoritative parenting (Baumrind, Larzelere, \& Owens, 2010; Georgiou, Ioannou, \& Stavrinides, 2017; Larzelere et al., 2013) and the authoritative school climate (Cornell \& Huang, 2016; Cornell et al., 2015; Gerlinger \& Wo, 2014; Gregory et al., 2010), it is plausible to assume that an authoritative classroom climate is a protective factor in preventing school bullying. Thus, we hypothesized that an authoritative classroom climate is associated with greater defender behavior, less reinforcer behavior, less outsider behavior, and less bullying victimization.

Gender was included as a covariate at the individual and classroom levels. Based on previous findings, we hypothesized that boys would be more engaged in reinforcer behavior than girls, and girls would be more engaged in defender behavior than boys, whereas we hypothesized that there would be no gender differences in bullying victimization. Due to the inconsistent findings in the literature, we did not assume a particular hypothesis on gender proportion at the classroom level, but simply included the variable as a covariate at the classroom level in an exploratory manner.

Social-ecological theory (Espelage \& Swearer, 2011) emphasizes that behaviors are produced by interdependent associations between individual and contextual factors. Therefore, we assumed that it would be possible to detect cross-level interaction effects between gender and an authoritative classroom climate. However, as empirical research on the subject is lacking, we were unable to deduce any clear hypotheses suitable for testing. We were able to examine possible cross-level interactions in an exploratory manner.

\section{Method}

\section{Participants}


The study participants consisted of 1540 fifth-grade students from 104 classrooms in 63 public schools located in 10 different municipalities in the south and middle of Sweden (age range $=10.42-13.08$ years, $M=11.55, S D=0.32)$. Of these, $716(46 \%)$ were boys and 824 (54\%) were girls. The students' self-reported ethnic background was mainly Swedish $(81.45 \%)$ (born in Sweden with at least one Swedish-born parent), whereas $18.55 \%$ had a foreign background (i.e., born in another country and/or both parents born in another country). We obtained parental consent (written) and student consent (oral) from all the participants.

\section{Procedure}

The participants completed a web-based questionnaire on tablets in their ordinary classroom settings with a member of the research team present. This researcher explained the study procedure, assured students of confidentiality, and assisted any participants who needed help.

\section{Measures}

Authoritative classroom climate. A 15-item scale was created to measure the authoritative classroom climate. The questionnaire began with the following question, "About your class and your teachers: How much do you agree with this?" This question was followed by items covering three subscales: teacher support, teacher structure, and student support (see Table 1). Cronbach's $\alpha$ for the whole scale was .94. The three-dimensional scale was confirmed by a confirmatory factor analysis (CFA) using the ULS estimator for ordinal data $\left(\mathrm{CFA}: \chi^{2}(87)=1117.239, p<.001, \mathrm{CFI}_{\text {robust }}=.996, \mathrm{RMSEA}_{\text {robust }}=.038 ; 90 \% \mathrm{CI}[.036\right.$, .040]). The authoritative classroom climate measure was obtained by computing the average score for each individual in the classroom and then obtaining the classroom mean.

Bullying victimization. An 11-item self-report scale was developed to measure bullying victimization. With reference to research showing that students might have various understandings of the word "bullying" (Frisén, Holmqvist, \& Oscarsson, 2008; Guerin \& 
Hennessy 2002; Purcell, 2012), and that the word itself is considered to be negatively valueloaded (Felix, Sharkey, Green, Furlong, \& Tanigawa, 2011) and associated with a risk of underreporting, our scale did not provide the word bullying with an a priori definition. Instead, it started with the question, "Think of the past three months: How frequently have one or more students who are stronger, more popular, or more in charge in comparison to you done the following things towards you?" The following behavioral items included physical, verbal, and relational bullying victimization. For each item, the student responded on a 5point scale from 1 = "Has never happened to me" to 5 = "Several times a week," Cronbach's $\alpha$ was .90 . The one-dimensional scale was confirmed by a CFA using the ULS estimator for ordinal data $\left(\mathrm{CFA}: \chi^{2}(44)=977.170, p<.001, \mathrm{CFI}_{\text {robust }}=.987, \mathrm{RMSEA}_{\text {robust }}=.076 ; 90 \% \mathrm{CI}\right.$ $[.072, .080])$. The bullying victimization score was obtained by computing the average score for each individual.

Bystander behavior. We used a three-dimensional 15 -item seven-point scale $(1=$ strongly disagree to $7=$ strongly agree) to measure students' bystander behavior (Thornberg, Wänström, Hong, \& Espelage, 2017) but removed the three assistant behavior items. Thus, the scale used in the analysis consisted of 12 items. Moreover, the word "bullying" was replaced with "victimizing" to reduce the risk of an underreporting of negative bystander responses. The participants were asked the following question, "Try to remember situations in which you have seen one or more students victimizing another student (e.g., teasing, mocking, threatening, physically assaulting, or freezing out). What do you usually do?" Two items depicted reinforcer behavior (e.g., "I laugh and cheer on those who victimized the kid," Spearman-Brown coefficient $=.59$ ), five items depicted outsider behavior (e.g., "I just walk away," Cronbach's $\alpha=.80$ ), and five items depicted defender behavior (e.g., "I help the victimized student," Cronbach's $\alpha=.81$ ). The three-dimensional solution was previously 
confirmed for the same sample (Author et al., 2018). The scores were obtained by computing the average score for each individual.

\section{Statistical Models}

Because students were nested within classrooms, we analyzed each dependent variable (defender behavior, reinforcer behavior, outsider behavior, and victimization) using random intercept regression models. In model 1, the individual predictor "gender" was entered. In model 2, class predictors "proportion of boys" and "authoritative classroom climate" were entered as well. Finally, in model 3, the interaction between gender and authoritative classroom climate was entered. Model 3 is shown below:

$$
D V_{i j}=\alpha_{j}+\beta_{1} \text { Gender }+\beta_{2} \text { P. boys }+\beta_{3} \text { Climate }+\beta_{4} \text { Gender } \times \text { Climate }+u_{j}+\epsilon_{i j}
$$

In this final equation, $\mathrm{DV}_{\mathrm{ij}}$ is the defending, reinforcing, outsider behavior, and victimization score, respectively, for the $\mathrm{i}$ :th student in the $\mathrm{j}$ :th class, $\alpha_{j}$ is the intercept in classroom $\mathrm{j}, \beta_{l}$ to $\beta_{4}$ are regression slopes, $\varepsilon_{i j}$ is a student residual, $\alpha$ is the mean intercept across classes, and $u_{j}$ is a classroom residual. It is assumed that $u_{j} \sim N\left(0, \sigma_{u}^{2}\right), \varepsilon_{i j} \sim N\left(0, \sigma_{\varepsilon}^{2}\right)$ and $\operatorname{cov}\left(u_{j}, \varepsilon_{i j}\right)=0$, where $\sigma_{u}^{2}$ is the variance between classrooms and $\sigma_{\varepsilon}^{2}$ is the variance within classrooms.

\section{Results}

Descriptive statistics for individual and class-level variables are shown in Table 2. Table 3 presents pairwise correlations between the dependent variables (class means) and the classroom variables. As can be seen, defender behavior was positively correlated, whereas reinforcer behavior, outsider behavior, and bullying victimization were negatively correlated with authoritative classroom climate. Reinforcer behavior was also positively correlated with the proportion of boys in the class. 
Table 4 shows the results of the variance component regression analyses with defender behavior, reinforcer behavior, outsider behavior, and bullying victimization as dependent variables. About $5 \%$ of the variance in defender behavior was between classes. Girls and students in classes with more authoritative classroom climates defended more than boys and students in classes with less authoritative classroom climates. For the reinforcer behavior, $3.5 \%$ of the variance was between classes. Boys reinforced more, as did students in classes with more boys and less authoritative classroom climates. In addition, the interaction between gender and authoritative classroom climate (Figure 1) indicates that the negative relationship between authoritative classroom climate and reinforcer behavior was steeper for boys (-.187) than for girls (-.048). In other words, boys were even more inclined than girls to reinforce bullying when they belonged to classrooms with a less authoritative climate. For outsider behavior, $10 \%$ of the variance was between classes. Boys showed more outsider behaviors, as did students in classes with less authoritative classroom climates. The negative relationship between outsider and authoritative classroom climate was steeper for boys (-.368) than for girls (-.115) (Figure 2). As in the case of reinforcer behavior, boys were more inclined than girls to remain as passive bystanders and adopt an outsider role when witnessing bullying if they belonged to classrooms with a less authoritative climate. Almost $9 \%$ of the variance in bullying victimization was between classes. Students in classrooms with less authoritative climates were victimized to a higher degree.

\section{Discussion}

Although an authoritative school climate has been linked to lower levels of bullying and victimization (Cornell \& Huang, 2016; Cornell et al., 2015; Gerlinger \& Wo, 2014; Gregory et al., 2010), relatively little is known about whether classroom climate is associated with bullying victimization and various bystander behaviors in school bullying. Victimization has been related to poor student-student relationships at the classroom level (Stefanek et al., 
2011) and lower levels of warm, caring, and supportive classroom climate (Thornberg, Wänström, \& Pozzoli, 2017), whereas defender behavior has been related to warm, caring, and supportive student-student relationships at the classroom level (Thornberg, Wänström, Hong, \& Espelage, 2017). This study was the first to test whether an authoritative classroom climate, measured as student perceptions of teacher structure, teacher support, and student support aggregated at the classroom level, was associated with bullying victimization, defender behavior, outsider behavior, and reinforcer behavior in school bullying.

Consistent with our hypotheses, and controlling for gender at the individual level and the proportion of boys at the classroom level, we found that students who belonged to classrooms with a more authoritative climate were less likely to be bullied in school. Moreover, when they were witnessing bullying or peer victimization, they were more inclined to defend, help, and support the victim and less prone to reinforce bullying by laughing and cheering or remaining passive and neutral as bystanders. Thus, the current findings suggest that an authoritative classroom climate functions as a protective classroom-level factor against bullying, both in reducing the risk of bullying victimization and enhancing the likelihood of bystander responses associated with a low prevalence of bullying. The finding showing that an authoritative classroom climate is related to greater defender behavior and less reinforcer behavior (i.e., bystanders who laugh and cheer) is novel and significant as previous research has shown that such a bystander reaction pattern among classmates is linked with less bullying (Kärnä et al., 2010; Nocentini et al., 2013; Salmivalli et al., 2011). Overall, our results support a social-ecological perspective in which contextual variables such as classroom climate and peer ecology at the class level are important factors in victimization and bystander behaviors (Espelage \& Swearer, 2011; Hong \& Espelage, 2012).

In terms of gender, the present findings showed, in accordance with our hypotheses and previous findings (e.g., Espelage et al., 2012; Gini et al., 2015; Pöyhönen et al., 2012; 
Thornberg \& Jungert, 2013), that girls were more inclined to defend victims, boys were more inclined to reinforce bullying, and there were no significant gender differences in bullying victimization. In addition, we found that boys as bystanders in bullying were more inclined than girls to take an outsider role as well. A possible explanation for these gender differences might be gender-specific socialization practices across various socialization agents, including parents, peers, teachers, other adults, and the media. Girls are encouraged to engage in nurturing and caring behaviors, whereas aggression is more socially acceptable for boys (Carlo, 2014). Furthermore, the interaction effects in the multilevel regression models suggest that boys are more inclined than girls to take reinforcer and outsider roles as bystanders when they belong to a classroom with poor teacher structure and less teacher and student support. Thus, boys seem to be more influenced than girls by a low authoritative classroom climate, considering their likelihood to act as reinforcers or outsiders in school bullying.

\section{Limitations}

Some of the limitations of this study are worth mentioning. First, we used self-reported data, which may have resulted in under- or over-estimation. However, to decrease the risk of under-reporting of bullying victimization, we did not include the term "bullying" in the bullying victimization scale. Still, self-reported data is vulnerable to various biases, including memory distortion and social desirability. Second, the reinforcer behavior subscale only included two items, which may have limited the full range of the construct as well as measuring the internal reliability. Third, the Authoritative Classroom Climate scale in the current study is a brand-new scale and its psychometric qualities need to be further tested. Fourth, we could not draw causal conclusions or pinpoint the direction of the identified relations among variables due to the cross-sectional design. Fifth, the sample has a very limited age span, and we did not control for socioeconomic background or ethnicity. Future studies should replicate the current findings with other samples of students of different age 
levels and from different cultural backgrounds, in which socioeconomic and ethnicity data are included in the analyses.

\section{Implications for Practice}

These limitations aside, the current study has important practical implications. The findings support the authoritative school climate model (Gregory \& Cornell, 2009; Gregory et al., 2010; Konold \& Cornell, 2015) by suggesting that teachers who create and maintain an authoritative classroom climate are a vital component of bullying prevention programs. In order to reduce the risk of bullying victimization, reinforcer behavior and outsider behavior, and to increase the probability of defender behavior among their students, teachers should design a classroom climate with strict but fair enforcement of rules and high expectations and demandingness, while building warm, caring, and supportive relationships with their students through modelling and relationship-building. Teachers should also develop strategies that encourage students to develop and maintain warm, caring, and supportive relationships with their classmates.

The findings also have implications for practicing school psychologists. First, they should have a better understanding of how an authoritative classroom climate is related to bullying victimization and bystander behaviors in order to support and counsel teachers in bullying prevention as a part of their classroom management. Second, in addition to a regular

student bullying questionnaire to measure bullying prevalence, school psychologists could use the authoritative classroom climate scale developed in the current study, or a similar scale, to screen classrooms with a less authoritative classroom climate and to provide interventions to increase both support and structure in the classroom. They should select and implement interventions that target both teacher support, teacher structure, and student support (e.g., feedback information based on student-reported data from the authoritative classroom scale; follow-up classroom observations to provide collegial support; and offering information and 
consultation on authoritative classroom management and authoritative classroom and school climate).

School psychologists need to inform teachers about how an authoritative classroom climate is not only linked to less bullying victimization but is also associated with fewer negative bystander behaviors (reinforcer and outsider behavior) - particularly among boys and more frequent defender behaviors. School psychologists might also introduce, support and monitor the implementation of suitable programs in the schools. One such program is the Child Development Project (Developmental Discipline) program, which is an evidence-based program to classroom management and discipline consistent with an authoritative approach to classroom management and climate. This program includes the development of warm, supportive, and mutually trusting teacher-student relationships, classrooms as caring, just and democratic learning communities, and classroom control with structure, guidance, and firm, consistent and explanation-oriented responses to misbehavior (Shaps, Battistich, \& Solomon, 2004; Solomon, Battistich, Watson, Schaps, \& Lewis, 2000; Watson, 2014). An authoritative teacher style is also prominent in the core principles behind the evidence-based Olweus Bullying Prevention Program (Olweus \& Limber, 2007). 


\section{References}

Álvarez-García, D., García, T., \& Núñez, J. C. (2015). Predictors of school bullying perpetration in adolescence: A systematic review. Aggression and Violent Behavior, 23, 126-136. doi: 10.1016/j.avb.2015.05.007

Atlas, R. S., \& Pepler, D. J. (1998). Observations of bullying in the classroom. The Journal of Educational Research, 92, 86-99. doi:10.1080/00220679809597580

Atria, M., Strohmeier, D., \& Spiel, C. (2007). The relevance of the school class as social unit for the prevalence of bullying and victimization. European Journal of Developmental Psychology, 4, 372-387. doi: 10.1080/17405620701554560

Baumrind, D. (1967). Child care practices anteceding three patterns of preschool behavior. Genetic Psychology Monographs, 75, 43-88.

Baumrind, D. (1971). Current patterns of parental authority. Developmental Psychology Monograph, 4, 1-103. doi: 10.1037/h0030372

Baumrind, D. (1989). Rearing competent children. In W. Damon (Ed.), Child development. Today and tomorrow (pp. 349-378). San Francisco: Jossey-Bass Publishers.

Baumrind, D., Larzelere, R. E., \& Owens, E. B. (2010). Effects of preschool parents' power assertive patterns and practices on adolescent development. Parenting: Science and Practice, 10, 157-201. doi: 10.1080/15295190903290790

Bear, G. G., Gaskins, C., Blank, J., \& Chen, F. F. (2011). Delaware school climate surveystudent: Its factor structure, concurrent validity, and reliability. Journal of School Psychology, 49, 157-174. doi: 10.1016/j.jsp.2011.01.001

Bradshaw, C. P., Waasdorp, T. E., Debnam, K. J., \& Johnson, S. L. (2014). Measuring school climate in high schools: A focus on safety, engagement, and the environment. Journal of School Health, 84, 593-604. doi: 10.1111/josh.12186 
Carlo, G. (2014). The development and correlates of prosocial moral behaviors. In M. Killen \& J. G. Smetana (Eds.), Handbook of moral development (2nd ed., pp. 208-234). New York, NY: Psychology Press.

Chester, K. L., Callaghan, M., Cosma, A., Donnelly, P., Craig, W., Walsh, S. \& Molcho, M. (2015). Cross-national time trends in bullying victimization in 33 countries among children aged 11, 13 and 15 from 2002 to 2010. European Journal of Public Health, 25(Suppl 2), 61-64. doi: 10.1093/eurpub/ckv029

Coelho, V. A., \& Sousa, V. (2018). Class-level risk factors for bullying and victimization in Portuguese middle schools. School Psychology International, 39, 121-137. doi: $10.1177 / 0143034317749992$

Cook, C. R., Williams, K. R., Guerra, N. G., Kim, T. E., \& Sadek, S. (2010). Predictors of bullying and victimization in childood and adolescence: A meta-analytic investigation. School Psychology Quarterly, 25, 65-83. doi: 10.1037/a0020149

Copeland, W. E., Wolke, D., Angold, A., \& Costello, E. J. (2013). Adult psychiatric outcomes of bullying and being bullied by peers in childhood and adolescence. JAMA Psychiatry, 70, 419-426. doi: 10.1001/jamapsychiatry.2013.504

Copeland, W. E., Wolke, D., Lereya, S. T., Shanahan, L., Worthman, C., \& Costello, E. J. (2014). Childhood bullying involvement predicts low-grade systemic inflammation into adulthood. Proceedings of National Academy of Sciences of the United States of America, 111, 7570-7575. doi: 10.1073/pnas.1323641111

Cornell, D. \& Huang, F. (2016). Authoritative school climate and high school student risk behavior: A cross-sectional multi-level analysis of student self-reports. Journal of Youth and Adolescence, 45, 2246-2259. doi: 10.1007/s10964-016-0424-3 
Cornell, D., Shukla, K., \& Konold, T. (2015). Peer victimization and authoritative school climate: A multilevel approach. Journal of Educational Psychology, 107, 1186-1201. doi: $10.1037 / \mathrm{edu} 0000038$

Espelage, D. L., Green, H. D., \& Polanin, J. (2012). Willingness to intervene in bullying episodes among middle school students: Individual and peer-group influences. Journal of Early Adolescence, 32, 776-801. doi: 10.1177/0272431611423017

Espelage, D. L., \& Swearer, S. M. (Eds.). (2011). Bullying in North American schools (2nd ed.). New York, NY: Routledge.

Evans-Lacko, S., Takizawa, R., Brimblecombe, N., King, D., Knapp, M., Maughan, B., \& Arsenault, L. (2017). Childhood bullying victimization is associated with use of mental health services over five decades: A longitudinal nationally representative cohort study. Psychological Medicine, 47, 127-135. doi: 10.1017/S0033291716001719

Felix, E. D., Sharkey, J. D., Green, J. G., Furlong, M. J., \& Tanigawa, D. (2011). Getting precise and pragmatic about the assessment of bullying: The development of the California Bullying Victimization Scale. Aggressive Behavior, 37, 234-247. doi: 10.1002/ab.20389

Fink, E., Patalay, P., Sharpe, H., \& Wolpert, M. (2018). Child- and school-level predictors of children's bullying behavior: A multilevel analysis in 648 primary schools. Journal of Educational Psychology, 110, 17-26. doi: 10.1037/edu0000204

Frisén, A., Holmqvist, K., \& Oscarsson, D. (2008). 13-year-olds' perception of bullying: Definitions, reasons for victimisation and experience of adults' response. Educational Studies, 34, 105-117. doi: 10.1080/03055690701811149

Georgiou, S. N., Ioannou, M., \& Stavrinides, P. (2017). Parenting styles and bullying in school: The mediating role of locus of control. International Journal of School \& Educational Psychology, 5, 226-242. doi: 10.1080/21683603.2016.1225237 
Gerlinger, J., \&Wo, J. C. (2014). Preventing school bullying: Should schools prioritize an authoritative school discipline approach over security measures? Journal of School Violence, 15, 133-157. doi: 10.1080/15388220.2014.956321

Gini, G. \& Pozzoli, T. (2013). Bullied children and psychosomatic problems: A metaanalysis. Pediatrics, 132, 720-729. doi: 10.1542/peds.2013-0614

Gini, G., Pozzoli, T., \& Bussey, K. (2015). The role of individual and collective moral disengagement in peer aggression and bystanding: A multilevel analysis. Journal of Abnormal Child Psychology, 43, 441-452. doi:10.1007/s10802-014-9920-7

Gregory, A. \& Cornell, D. (2009). “Tolerating” adolescent needs: Moving beyond zero tolerance policies in high school. Theory into Practice, 48, 106-113. doi: $10.1080 / 00405840902776327$

Gregory, A., Cornell, D., Fan, X., Sheras, P., Shih, T-H. \& Huang, F. (2010). Authoritative school discipline: High school practices associated with lower bullying and victimization. Journal of Educational Psychology, 102, 483-496. doi: $10.1037 / \mathrm{a} 0018562$

Guerin, S., \& Hennessey, E. (2002). Pupils' definitions of bullying. European Journal of Psychology of Education, 12, 249-261. doi: 10.1007/bf03173535

Hawkins, D. L., Pepler, D. J., \& Craig, W. M. (2001). Naturalistic observations of peer interventions in bullying. Social Development, 10, 512-527. doi:10.1111/14679507.00178

Hattie, J. (2009). Visible learning: A synthesis of over 800 meta-analyses relating to achievement, London: Routledge.

Holt, M. K., Vivolo-Kantor, A. M., Polanin, J. R., Holland, K. M., DeGue, S., Matjasko, J. L., Wolfe, M., \& Reid, G. (2015). Bullying and suicidal ideation and behaviors: A metaanalysis. Pediatrics, 135, e496-e509. doi: 10.1542/peds.2014-1864 
Hong, J. S., \& Espelage, D. L. (2012). A review of research on bullying and peer victimization in school: An ecological system analysis. Aggression and Violent Behavior, 17, 311-322. doi: 10.1016/j.avb.2012.03.003

Kärnä, A., Voeten, M., Poskiparta, E., \& Salmivalli, C. (2010). Vulnerable children in different classrooms: Classroom-level factors moderate the effect of individual risk on victimization. Merrill-Palmer Quarterly, 56, 261-282. doi:10.1353/mpq.0.0052

Konishi, C., Miyazaki, Y., Hymel, S., \& Waterhouse, T. (2017). Investigating associations between school climate and bullying in secondary schools: Multilevel contextual effects modeling. School Psychology International, 38, 240-263. doi: $10.1177 / 0143034316688730$

Konold, T. R., \& Cornell, D. (2015). Measurement and structural relations of an authoritative school climate model: A multi-level latent variable investigation. Journal of School Psychology, 53, 447-461. doi: 10.1016/j.jsp.2015.09.001

Larzelere, R. E., Morris, A. S., \& Harrist, A. W. (Eds.) (2013). Authoritative parenting: Synthesizing nurturance and discipline for optimal child development. Washington, DC: American Psychological Association.

La Salle, T., George, H. P., McCoach, B., Polk, T., \& Evanovich, L. L. (2018). An examination of school climate, victimization, and mental health problems among middle school students self-identifying with emotional and behavioral disorders. Behavioral Disorders, 43, 383-392. doi: 10.1177/0198742918768045.

Meltzer, H., Vostanis, P., Ford, T., Bebbington, P. \& Dennis, M. S. (2011). Victims of bullying in childhood and suicide attempts in adulthood. European Psychiatry, 26, 498503. doi: 10.1016/j.eurpsy.2010.11.006

Modin, B., Låftman, S. B., \& Östberg, V. (2017). Teacher rated school ethos and student reported bullying: A multilevel study of upper secondary schools in Stockholm, 
Sweden. International Journal of Environmental Research and Public Health, 14, Art. 1565. doi: 10.3390/ijerph14121565.

Nocentini, A., Menesini, E., \& Salmivalli, C. (2013). Level and change of bullying behavior during high school: A multilevel growth curve analysis. Journal of Adolescence, 36, 495-505. doi: 10.1016/j.adolescence.2013.02.004

Olweus, D. (2010). Understanding and researching bullying: Some critical issues. In S. R. Jimerson, S. M. Swearer, \& D. L. Espelage (Eds.), Handbook of bullying in schools: An international perspective (pp. 9-33). New York, NY: Routledge.

Olweus, D., \& Limber, S. P. (2007). Olweus bullying prevention program: Teacher guide. Center City, MN: Hazelden.

Pöyhönen, V., Juvonen, J., \& Salmivalli, C. (2012). Standing up for the victim, siding with the bully or standing by? Bystander responses in bullying situations. Social Development, 21, 722-741. doi:10.1353/mpq.0.0046

Purcell, A. (2012). A qualitative study of perceptions of bullying in Irish primary schools. Educational Psychology in Practice, 28, 273-285. doi: 10.1080/02667363.2012.684343

Ramolow, D., Currie, D., \& Felder-Puig, R. (2015). The assessment of school climate: Review and appraisal of published student-report measures. Journal of Psychoeducational Assessment, 33, 731-743. doi: 10.1177/0734282915584852

Saarento, S., Garandeau, C. F., \& Salmivalli, C. (2015). Classroom- and school-level contributions to bullying and victimization: A review. Journal of Community \& Applied Social Psychology, 25, 204-218. doi: 10.1002/casp.2207

Salmivalli, C. (1999). Participant role approach to school bullying: Implications for interventions. Journal of Adolescence, 22, 453-459. doi: 10.1006/jado.1999.0239 
Salmivalli, C., Voeten, M., \& Poskiparta, E. (2011). Bystanders matter: Associations between reinforcing, defending, and the frequency of bullying in classrooms. Journal of Clinical Child and Adolescent Psychology, 40, 668-676. doi:10.1080/15374416.2011.597090

Schaps, E., Battistich, V., \& Solomon, D. (2004). Community in school as key to student growth: Findings from the Child Development Project. In J. E. Zins, R. P. Weissberg, M. C. Wang, \& H. J. Walberg (Eds.), Building academic success on social and emotional learning: What does research say? (pp. 189-205). New York, NY: Teachers College.

Silberg, J. L., Copeland, W., Linker, J., Moore, A. A., Roberson-Nay, R., \& York, T. P. (2016). Psychiatric outcomes of bullying victimization: A study of discordant monozygotic twins. Psychological Medicine, 46, 1875-1883. doi:

$10.1017 / \mathrm{S} 0033291716000362$

Solomon, D., Battistich, V., Watson, M., \& Schaps, E., \& Lewis, C. (2000). A six-district study of educational change: Direct and mediated effects of the child developmental project. Social Psychology of Education, 4, 3-51.

Stefanek, E., Strohmeier, D., van de Schoot, R., \& Spiel, C. (2011). Bullying and victimization in ethnically diverse schools: Risk and protective factors on individual and class level. International Journal of Developmental Science, 5, 73-84. doi: 10.3233/DEV-2011-11073

Thapa, A., Cohen, J., Guffey, S., \& Higgins-D’ Alessandro, A. (2013). A review of school climate research. Review of Educational Research, 83, 357-385. Doi: $10.3102 / 0034654313483907$

Thornberg, R., \& Jungert, T. (2013). Bystander behavior in bullying situations: Basic moral sensitivity, moral disengagement and defender self-efficacy. Journal of Adolescence, 36, 475-483. doi:10.1016/j.adolescence.2013.02.003 
Thornberg, R., Wänström, L., Hong, J. S., \& Espelage, D. L. (2017). Classroom relationship qualities and social-cognitive correlates of defending and passive bystanding in school bullying in Sweden: A multilevel analysis. Journal of School Psychology, 63, 49-62. doi:10.1016/j.jsp.2017.03.002

Thornberg, R., Wänström, L., \& Pozzoli, T. (2017). Peer victimisation and its relation to class relational climate and class moral disengagement. Educational Psychology, 37, 524536. doi: 10.1080/01443410.2016.1150423

Wang, M-T., \& Degol, J. L. (2016). School climate: A review of the construct, measurement, and impact on student outcomes. Educational Psychology Review, 28, 315-352. doi: $10.1007 / \mathrm{s} 10648-015-9319-1$.

Watson, M. (2014). Developmental discipline and moral education. In L. Nucci, D. Narvaez, \& T. Krettenauer (Eds.), Handbook of moral and character education (2nd ed., pp. 159-179). New York, NY: Routledge

White, N., La Salle, T., Ashby, J. S., \& Meyers, J. (2014). A brief measure of adolescent perceptions of school climate. School Psychology Quarterly, 29, 349-359. doi: $10.1037 / \mathrm{spq} 0000075$

Zedan, R. (2010). New dimensions in the classroom climate. Learning Environments Research, 13, 75-88. doi: 10.1007/s10984-009-9068-5

Zullig, K. J., Koopman, T. M., Patton, J. M., \& Ubbes, V. A. (2010). School climate: Historical review, instrument development, and school assessment. Journal of Psychoeducational Assessment, 28, 139-152. doi: 10.1177/0734282909344205 
Table 1. The list of items in the Authoritative classroom climate scale (including Cronbach's $\alpha$ of the subscales).

\begin{tabular}{|c|c|c|}
\hline Subscales & Items & $\alpha$ \\
\hline $\begin{array}{l}\text { Teacher } \\
\text { support }\end{array}$ & $\begin{array}{l}\text { 2. Our teachers really care about the students } \\
\text { 5. Our teachers really give the students good support and help } \\
\text { 10. Our teachers listen to the students when they have problems } \\
\text { 13. Our teachers like the students }\end{array}$ & .89 \\
\hline $\begin{array}{l}\text { Teacher } \\
\text { structure }\end{array}$ & $\begin{array}{l}\text { 4. Our teachers bring order and undisturbed working atmosphere in the } \\
\text { classroom } \\
\text { 7. Our teachers make clear demands on students } \\
\text { 11. Our teachers keep an eye on the students } \\
\text { 14. Our teachers are good at getting the students to follow the rules }\end{array}$ & .81 \\
\hline $\begin{array}{l}\text { Student } \\
\text { support }\end{array}$ & $\begin{array}{l}\text { 1. The students are decent to each other in our class } \\
\text { 3. All students in our class can feel safe } \\
\text { 6. The students in our class get along well with each other } \\
\text { 8. The students are kind and nice to each other in our class } \\
\text { 9. It's a good atmosphere in our class peer group } \\
\text { 12. The students are caring towards each other in our class } \\
\text { 15. The students in our class treat each other with respect }\end{array}$ & .94 \\
\hline
\end{tabular}

Table 2. Number of observations, means, standard deviations, min- and max scores for individual- and class level variables.

\begin{tabular}{llllll}
\hline & $\mathrm{n}$ & Mean & St.Dev & Min & Max \\
\hline Defend & 1540 & 5.405 & 1.295 & 1.000 & 7.000 \\
Reinf & 1540 & 1.190 & .666 & 1.000 & 7.000 \\
Outsider & 1540 & 2.569 & 1.294 & 1.000 & 7.000 \\
Victim & 1540 & 1.539 & .618 & 1.000 & 5.000 \\
Climate & 104 & 5.475 & .610 & 3.733 & 6.614 \\
P.boys & 104 & .517 & .116 & .033 & .789 \\
\hline
\end{tabular}


Table 3. Correlations for class level variables $(n=104)$

\begin{tabular}{lllllll}
\hline & 1 & 2 & 3 & 4 & 5 & 6 \\
\hline 1.Defend & 1 & $-.264^{* *}$ & $-.421^{* * *}$ & -.084 & $.293^{* *}$ & -.227 \\
2.Reinf & 1 & .179 & $.273^{* *}$ & $-.362^{* * *}$ & $.310^{* *}$ \\
3.Outsider & & 1 & $.310^{* *}$ & $-.280^{* *}$ & .035 \\
4.Victim & & & 1 & $-.501^{* * *}$ & .127 \\
5.Climate & & & & 1 & -.153 \\
6.P.boys & & & & & & 1 \\
\hline
\end{tabular}

Note. ${ }^{*} p<.05,{ }^{* *} p<.01,{ }^{* * *} p<.005$. Class mean scores are used for the individual variables defender, reinforcer, outsider, and victimization.

Table 4. Regression coefficient estimates and standard deviations from variance component regression models.

\begin{tabular}{|c|c|c|c|c|c|c|c|c|}
\hline & \multicolumn{2}{|c|}{ Defend } & \multicolumn{2}{|c|}{ Reinf } & \multicolumn{2}{|c|}{ Outsider } & \multicolumn{2}{|c|}{ Victim } \\
\hline & Estimate & St.Dev & Estimate & St.Dev & Estimate & St.Dev & Estimate & St.Dev \\
\hline Model I & & & & & & & & \\
\hline $\begin{array}{l}\text { Gender } \\
\text { Model II }\end{array}$ & $.521^{* * *}$ & .064 & $-.155^{* * *}$ & .034 & $-.206^{* *}$ & .064 & .034 & .031 \\
\hline Gender & $.512^{* * *}$ & .065 & $-.143^{* * *}$ & .034 & $-.208^{* *}$ & .065 & .034 & .031 \\
\hline P.boys & -.032 & .353 & $.378^{*}$ & .168 & -.173 & .433 & .264 & .178 \\
\hline $\begin{array}{l}\text { Climate } \\
\text { Model III }\end{array}$ & $.254^{* * *}$ & .065 & $-.113^{* * *}$ & .031 & $-.234 * *$ & .080 & $-.190 * * *$ & .033 \\
\hline Gender & $.517^{* * *}$ & .065 & $-.142 * * *$ & .034 & $-.208^{* *}$ & .065 & .038 & .031 \\
\hline P.boys & -.034 & .353 & $.380 *$ & .169 & -.172 & .431 & .265 & .178 \\
\hline Climate & $.348^{* * *}$ & .086 & $-.187 * * *$ & .043 & $-.368^{* * *}$ & .097 & $-.209 * * *$ & .043 \\
\hline $\begin{array}{l}\text { Genderx } \\
\text { Climate }\end{array}$ & -.176 & .105 & $.139 *$ & .055 & $.253^{*}$ & .105 & .037 & .050 \\
\hline ICC & .052 & & .035 & & .100 & & .088 & \\
\hline
\end{tabular}




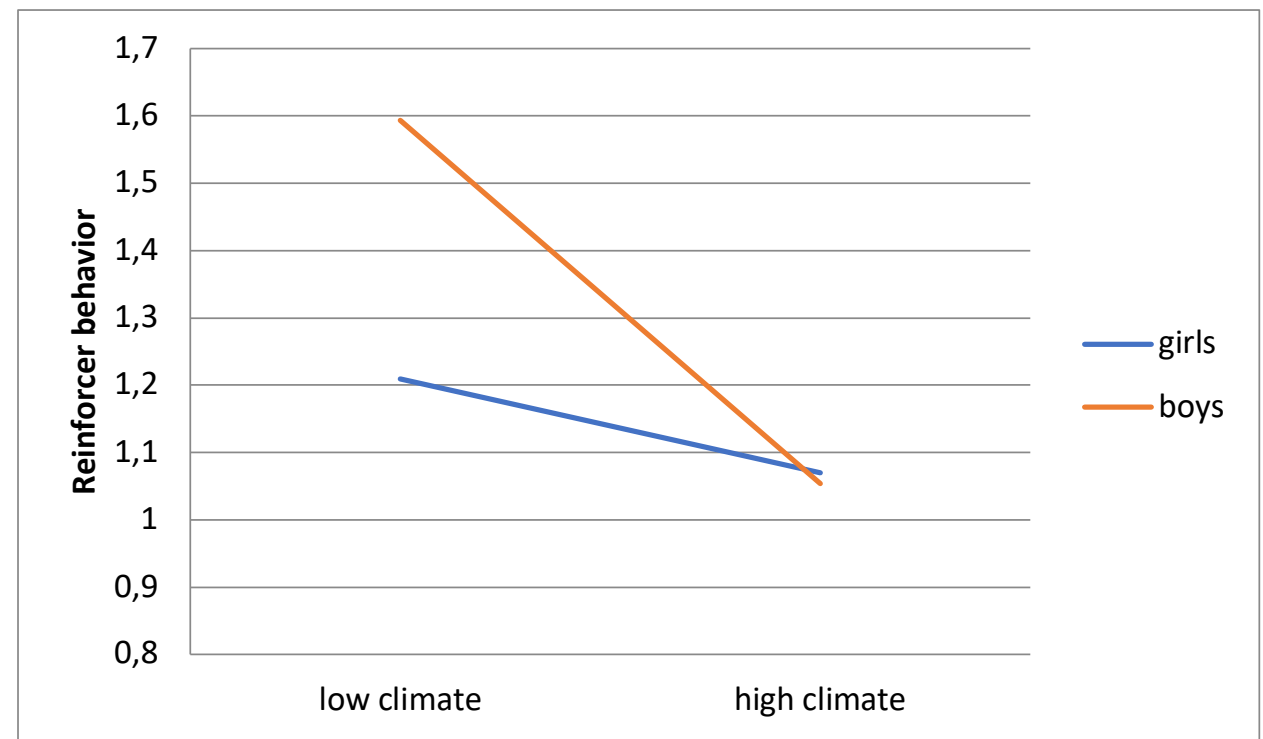

Figure 1. Illustration of interaction effect between gender and authoritative classroom climate for reinforcing behaviors. Note: climate $=$ authoritative classroom climate.

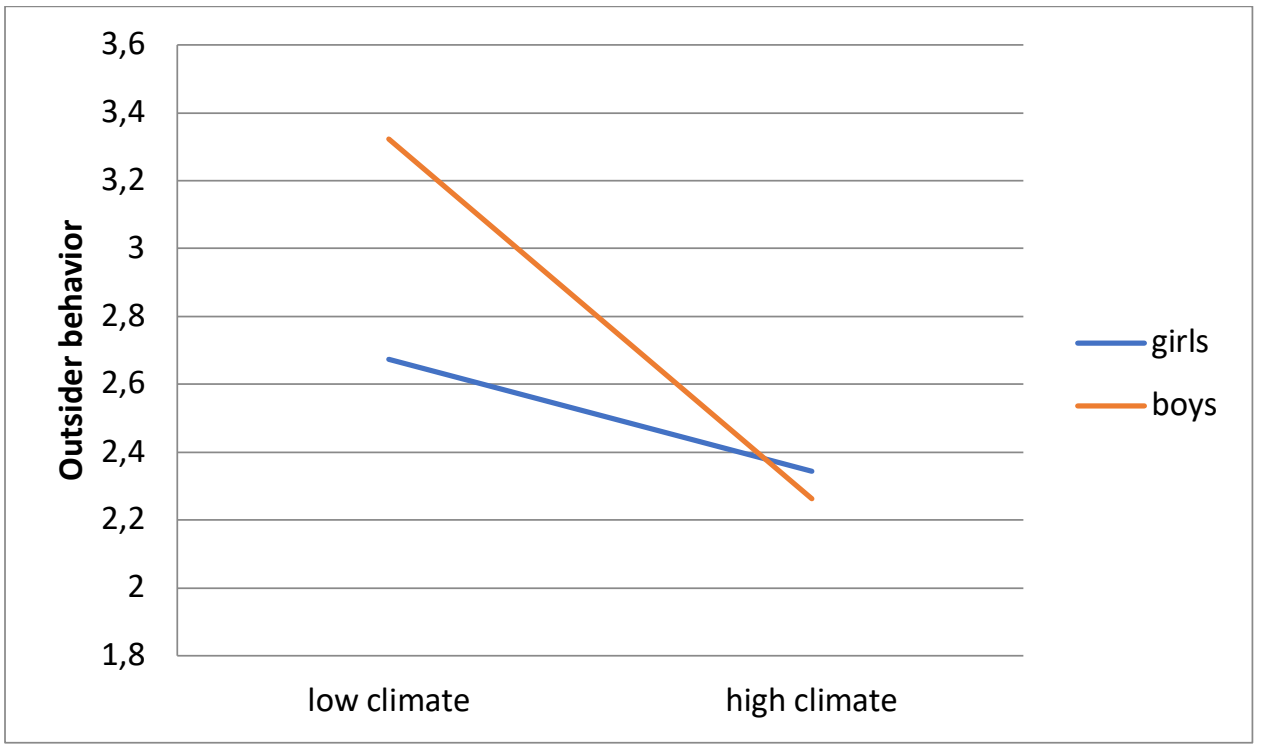

Figure 2. Illustration of interaction effect between gender and authoritative classroom climate for outsider behaviors. Note: climate $=$ authoritative classroom climate . 